\title{
Design and Analysis of a Wearable Monopole Antenna on Jeans Substrate for RFID Applications
}

\author{
Hammad Khan, Ali Nasir, Umar Bin Mumtaz, Sadiq Ullah*, Syed Ahson Ali Shah, \\ Muhammad Fawad Khan, Usman Ali
}

Department of Telecommunication Engineering, University of Engineering and Technology,Peshawar, Pakistan

\begin{abstract}
In this paper a novel rectangular $C$-shaped planar monopole antenna is designed and analyzed for Radio Frequency Identification (RFID) application in the licensed-free Industrial Scientific and Medical (ISM) band of $2.45 \mathrm{GHz}$. The proposed antenna uses a $1 \mathrm{~mm}$ thicker wearable Jeans fabric \{relative permittivity, $\varepsilon_{\mathrm{r}}=1.68$ and Loss Tangent of $\delta=0.025\}$ as a substrate material. For better bandwidth, and radiation efficiency the substrate is backed by a truncated copper ground plane. The antenna operate efficiently (92.85\%), giving an adequate bandwidth, return-loss, gain and directivity of $12 \%,-35.57 \mathrm{~dB}, 3.144 \mathrm{~dB}$ and $3.465 \mathrm{dBi}$, respectively. The nominated antenna is compact, low profile, and provides a better impedance matching ( $50.25 \mathrm{ohms})$ which results in a Voltage Standing Wave Ratio (VSWR) of 1.03. The far-field analysis is carried out via Finite Integration Technique (FIT) in CST Microwave studio.
\end{abstract}

Index Terms: Planar antenna, radio frequency identification, wearable, monopole, low profile.

(C) 2016 Published by MECS Publisher. Selection and/or peer review under responsibility of the Research Association of Modern Education and Computer Science

\section{Introduction}

With the advent in modern communication systems, RFID ( Radio Frequency Identification) is graded at a higher place than Traditional Identification Methods (TIM), e. g. Bar Code Scanning, over the past decade leading a huge number of commercialization and research endeavor in the early 2000s [1]. Due to the excellent performance in the field of automatic identification and data collection, RFID technology is broadly used, and different frequency ranges have been assigned depending upon the RFID applications. The specific frequency ranges includes 120-150 KHz (LF-Unregulated), $13.56 \mathrm{MHz}$ (HF-ISM BAND), 865-868 MHz (UHF-ISM BAND), $\quad(2.45 \mathrm{GHz}) \quad 2.400-2.483 \quad \mathrm{GHz} \quad$ (Microwave-ISM $\quad$ BAND),(5.8 GHz) $\quad 5.725-5.875 \quad \mathrm{GHz}$

\footnotetext{
* Corresponding author. Tel.: 0092937 9230295; fax: 00929379230296
}

E-mail address: sadiqullah@uetpeshawar.edu.pk 
(Microwave-ISM BAND). The maximum data rate transfer and the higher ranges are achieved on higher frequencies (Microwave-Region). In RFID microwave (MW) region (2.45/5.8 GHz), the layout of an antenna becomes more knotty and crucial [2]. The Basic composition of the passive UHF and microwave frequencies (MWF), RFID systems are a tag with some stored information, linked to an object and the tag is activated by electromagnetic waves (EM) imparted by the reader. Communication is processed when the backscatter radio waves are modulated by the data stored in the tag. RFID tags are widely in various fields of automatic identification of objects such as access control, asset identification and industry manufacture and much more [3]. RFID is the most suitable way to communicate with wireless body area network (WBANs) through their backscattered radio waves. In back scattered system, the communication between the tag and the reader is ensured to be power efficient. The radio propagation channel and the efficiency of back scattered performance of on-body RFID system is obligatory to inspect in order to make sure, in reasonable ways the on-body RFID system's communication and the power delivered is durable [4].

The perception behind the idea of wearable computing systems become very trendy and it narrates the imminent of electronic systems as an elemental part of our clothes. The wearable systems, in the start, were used for navigation tasks, military operations, and surveillance purposes [5]. With the development in recent years, the technology has given us a podium in antenna that can be labelled as wearable antenna. These wearable antennas can be efficiently used for monitoring and indication. The ease of these labelled antennas is light weight, low cost and a reliable structure. The recent researches show that the flawless location for these antennas is the anatomy of the human body [6]. The life of human beings these days is glimmered with the sustained monitoring system. This technology is simply the imminent of smart garments and human life [7]. Due to the appealing characteristics (reliable structure, low-profile, light weight) of these antennas, researchers aim is to design an efficient wearable monopole antenna [8-9]. Radiating elements of various shapes have been designed till time e-g E-shaped [10], B-shaped [11], F-shaped [12], G-shaped [13], Double-T-shaped [14] and triangular shape [15]. In [16] a compact RFID antenna, operating in the unlicensed $60 \mathrm{GHz}$ millimeter wave band is presented. The advantage of the $60 \mathrm{GHz}$ frequency is the availability of the higher bandwidth in this band, which can support higher data rates and more RFID channels and services. The disadvantage of this technology is that the size of the antenna is extremely small at very high frequency $(60 \mathrm{GHz})$ which makes the fabrication quite challenging.

It is evident from Fig. 1 that the RFID tag antenna technology is an important component of modern industrial sectors [1] mainly used in:

- Manufacturing, logistics, distribution

- Asset management

- Access and quality control

- Payment

- Product, inventory tracking and item location

- Identification and inspection 


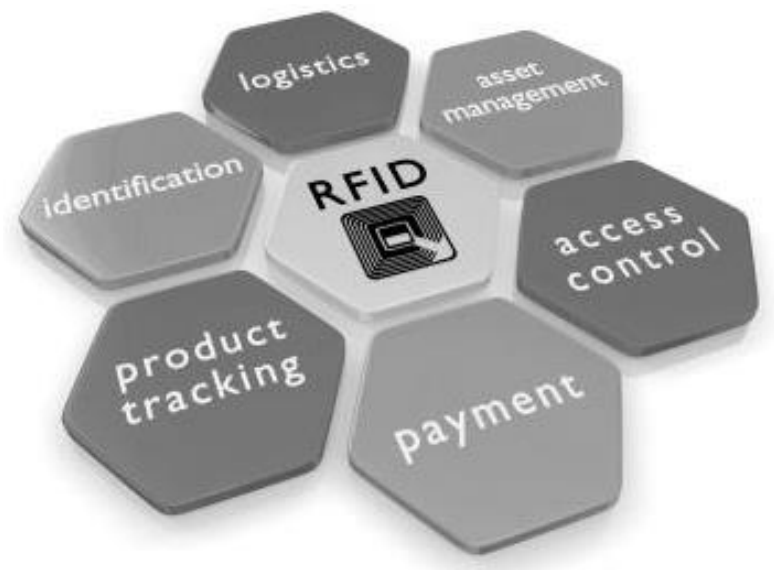

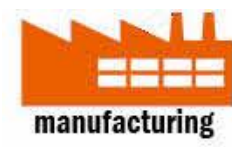

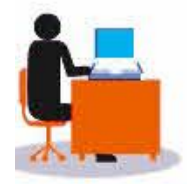

PROCESS/QC TRACKING

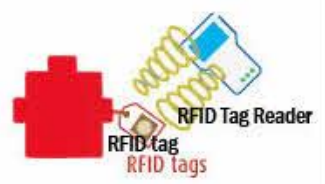

SHIPPING INSPECTION
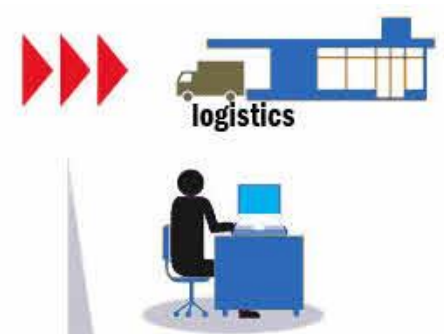

INVENTORY TRACKING

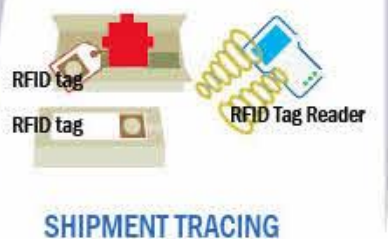

W
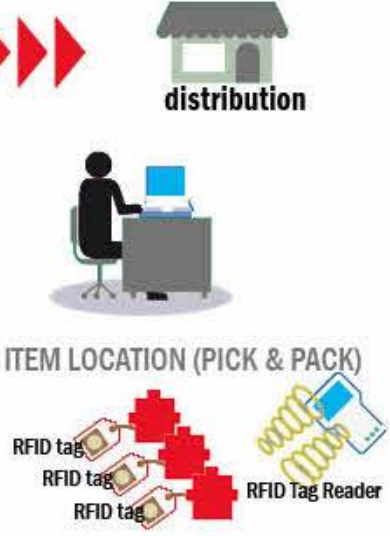

REPLENISHMENT

Fig.1. Applications of RFID Tag antennas

In this paper a rectangular C-shaped antenna is designed on 1-mm thick Jeans substrate with a truncated copper ground plane. The main objective is to design and analyze a $2.45 \mathrm{GHz}$ wearable monopole planar antenna for RFID applications. On the basis of simulated results, it is found that the nominated antenna gives superior performance in context of efficiency, reflection coefficient $\left(S_{11}\right)$, directivity, gain and bandwidth.

The rest of the research work is organized as follow: Segment 2 shows the theory and layout of planar monopole antenna. Segment 3 portrays the simulation and calculated results. The conclusion and future work of this research is stated in segment 4.

\section{Antenna Layout and Theory}

This section explains the layout and design theory of the proposed RFID antenna. The antenna is designed using the standard transmission line theory [17]. The antenna is excited using a waveguide port assigned to a microstrip feed line of width $(F W 1)$. For better bandwidth and efficiency, a truncated metallic ground plane is used beneath the substrate. 


\subsection{Layout}

The layout of the rectangular C-shaped, $2.45 \mathrm{GHz}$ RFID antenna is demonstrated in Fig. 2. The proposed antenna is backed by a $1 \mathrm{~mm}$ thicker Jeans substrate. A trimmed copper ground plane is used in order to achieve optimal efficiency and gain. The feed of the antenna is a $50 \Omega$ copper micro-strip line. The width $(\mathrm{Fw}=5 \mathrm{~mm})$ of the microstrip feed-line is calculated using [17]. The feed-line is connected with the radiating element of the antenna at a convenient driving point position, which results in a good impedance matching, low reflection coefficient and voltage standing wave ratio. In other words for better radiation efficiency the driving point impedance of the antenna must be closely comparable with the feed-line impedance.
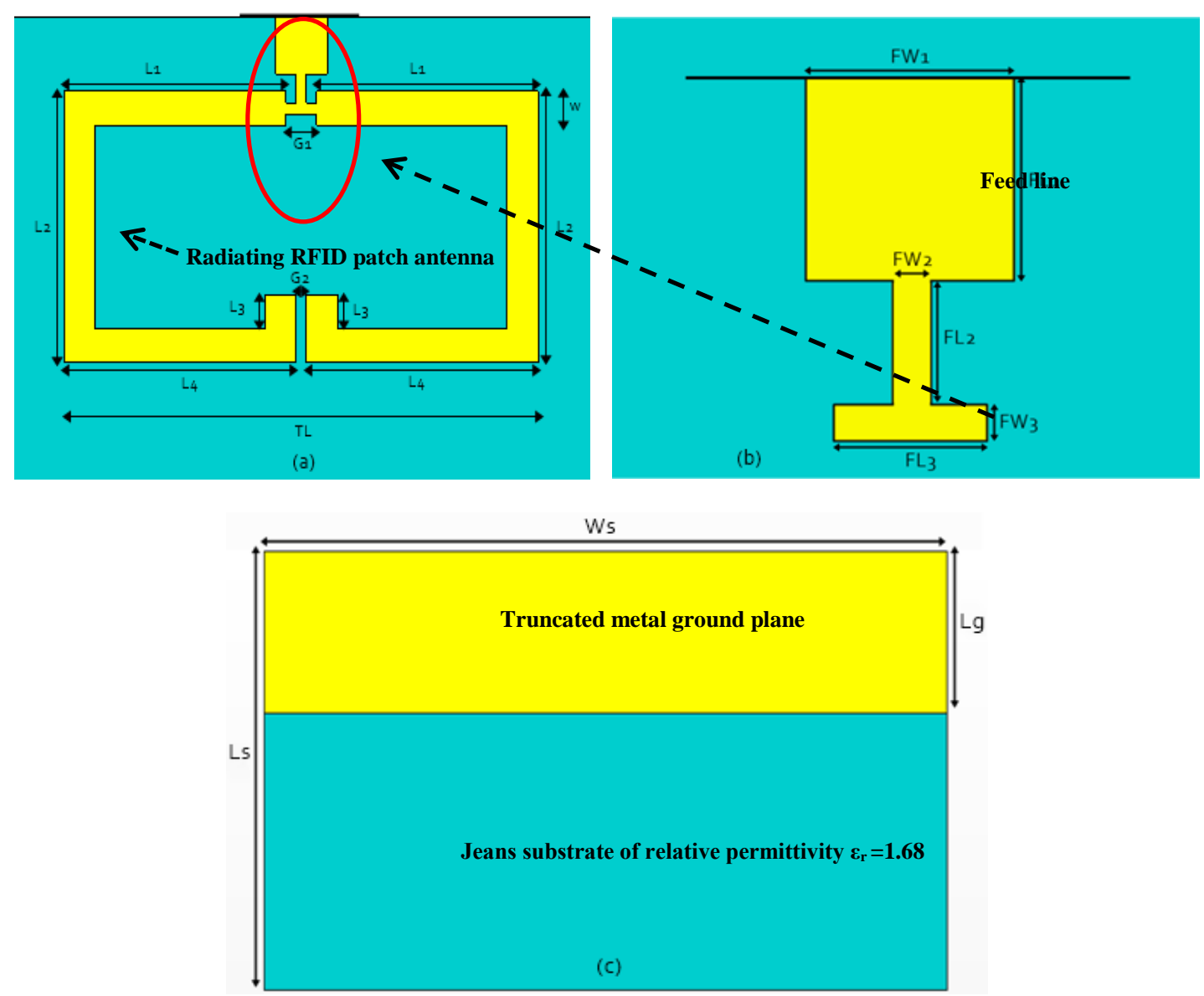

Fig.2. Layout of the proposed RFID antenna (a) front view (b) Zoomed View of Feed, (c) Rear View

In addition to compact size, the antenna is designed using a flexible and wearable jeans substrate material, which makes it a suitable candidate for body worn RFID applications.

The various dimensions of the proposed antenna are encapsulated in Table 1. 
Table 1. The dimensional parameters of Fig. 2

\begin{tabular}{llll}
\hline Parameters & Values $(\mathrm{mm})$ & Parameters & Values $(\mathrm{mm})$ \\
\hline L1 & 18.5 & FL1 & 10 \\
L2 & 24 & FL2 & 5 \\
L3 & 2.3 & FL3 & 3 \\
L4 & 19.5 & FW1 & 5 \\
G1 & 3 & FW2 & 1 \\
G2 & 1 & FW3 & 1 \\
W & 3 & TL & 40 \\
Ws & 90 & Lg & 18 \\
Ls & 50 & hs & 1 \\
\hline
\end{tabular}

\subsection{Theory}

Recalling the theory of transmission lines [17], effective length of the nominated antenna is found, that is $L_{2.45}=140.6 \mathrm{~mm}=2(\mathrm{~L} 1+\mathrm{L} 2+\mathrm{L} 3+\mathrm{L} 4+2 \mathrm{~W})$. The resonant length, $L_{2.45}$, in terms of guided wavelength, $\lambda_{2.45}$ is found using the following equation:

$L_{2.45}=\frac{\lambda_{2.45}}{4}$

Where, $\lambda_{2.45}$ is the guided wavelength of the waves within the substrate at resonant frequency, $f_{r}=2.45 \mathrm{GHz}$. It is found using:

$$
\lambda_{2.45}=\frac{c}{f_{r} \sqrt{\varepsilon_{r}}}
$$

Where, $c$ is speed of light, $\varepsilon_{r}$. is effective permittivity of the substrate [17]. The inclusive volume of the nominated antenna is $90 * 50 * 1 \mathrm{~mm} 3$.

The dimensions of the proposed antenna are optimized for better radiation efficiency $\left(\eta_{\text {rad }}\right)$, which is defined as the ratio of the radiated power of the antenna to its input power.

$$
\eta_{\text {rad }}=\frac{\text { Radiated power }}{\text { Input Power }}
$$

The efficiency is higher if the antenna is fed at the right point, resulting in minimum value of reflection coefficient $(\Gamma)$. This factor is the ratio of reflected and incident electric fields. Mathematically it is quantified as:

$$
|\Gamma|=\frac{Z_{a}-z_{0}}{Z_{a}+Z_{0}}
$$

Where, $Z_{a}$ is the driving point impedance of the antenna and $Z_{o}$ is the characteristic impedance of the microstrip feed line. Reflection coefficient, voltage standing wave ratio (VSWR) and return loss are interrelated parameters of the antenna, i.e. mathematically:

$$
\operatorname{VSWR}=\frac{1+|\Gamma|}{1-|\Gamma|}
$$


If reflection coefficient is small then VSWR approaches unity. The return loss is the ratio of the reflected power to the incident power of the antenna and is usually expressed in decibel (dB) scale.

$$
\text { Return Loss }(d B)=\frac{\text { Reflected Power }}{\text { Input Power }}=-20 \log _{10}|\Gamma|
$$

Lower value of return loss at the design frequency is achieved if the antenna is properly matched (i.e. low $\Gamma$ ). The gain $(G)$ and directivity $(D)$ of the proposed antenna are related by the radiation efficiency as:

$$
G=\eta_{\text {rad }} D
$$

\section{Results}

The nominated C-Shaped monopole antenna is sketched and inspected by a technique called FIT (Finite Integration Technique) in CST Microwave Studio [18]. The boundary conditions are taken as 'open add space' and using normal (free-space) background material. The transient solver is used to analyze the antenna performance parameters (i.e. return loss, VSWR, gain, directivity and surface electric field plots).

The antenna is excited through a waveguide port assigned to the $5 \mathrm{~mm}$ wide transmission feed line. Scattering parameters, return-loss, surface electric fields, gain and directivity in E and H-planes are figured out using open add space boundary conditions using the transient solver. The nominated antenna operates at 2.45 $\mathrm{GHz}$ with a return loss $(R L)$ of $-35.57 \mathrm{~dB}$. The antenna gives bandwidth of $12 \%$ at $2.45 \mathrm{GHz}$, relative to return loss $\leq-10 \mathrm{~dB}$, as highlighted in Fig. 3 .

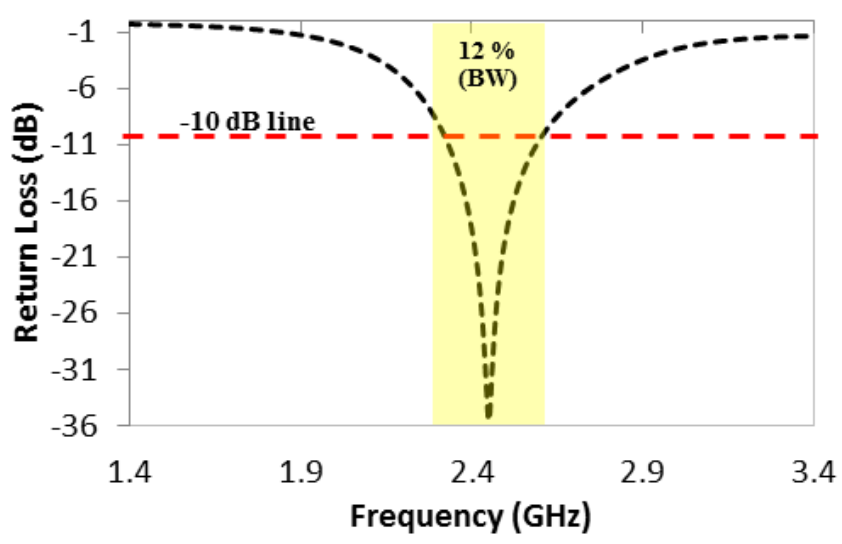

Fig.3. $\mathrm{S}_{11}$ Return loss(RL) in single frequency mode.

The Voltage Standing Wave Ratio (VSWR) of the nominated antenna is 1.03 at $2.45 \mathrm{GHz}$ (Fig. 4). It shows that the nominated antenna is perfectly matched i.e. having driving point impedance of $50.25 \Omega$ at $2.45 \mathrm{GHz}$ frequency. Hence the available input power to the antenna is predominantly radiated in the desired direction, with no (or extremely low power) reflected in the reverse direction. In other words the propagation of the standing waves along the feed line is highly restricted due to the impedance matching which helps in achieving very good radiation efficiency by the proposed RFID antenna. 


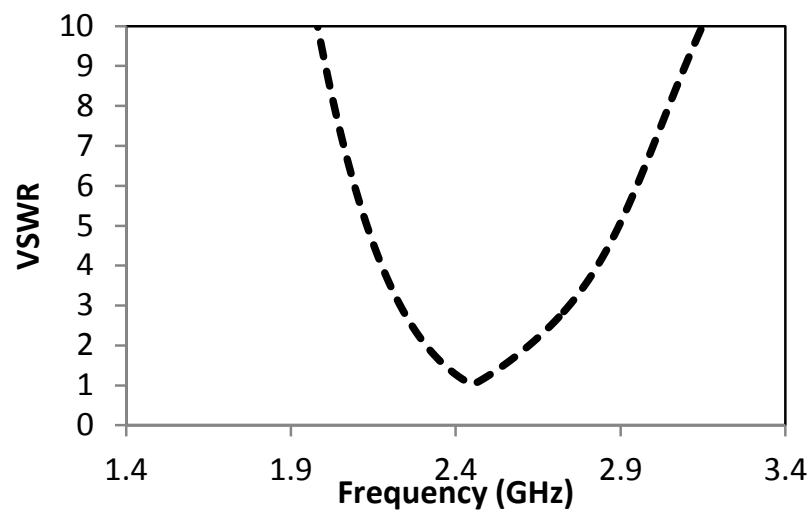

Fig.4. VSWR of the proposed antenna

The directivity patterns of the nominated monopole antenna in the $\mathrm{E}$ and $\mathrm{H}$-plane at $2.45 \mathrm{GHz}$ are portrayed in Fig. 5a. The nominated antenna gives a peak value of E-plane directivity $(3.465 \mathrm{dBi})$ at $2.45 \mathrm{GHz}$. The gain patterns of the nominated monopole antenna in the $\mathrm{E}$ and $\mathrm{H}$-plane at $2.45 \mathrm{GHz}$ is depicted in Fig. $5 \mathrm{~b}$. The antenna gives an $E$-plane gain of $3.144 \mathrm{~dB}$ at $2.45 \mathrm{GHz}$. The antenna radiates maximum power along the boresight direction $\left(\theta=0^{\circ}\right)$. These plots show that the given antenna radiates predominantly Omni-directionally in the $H$-plane. A single null in radiation pattern appears at $90^{\circ}$ in the $E$-plane radiation pattern of the antenna. The directivity and gain of the proposed antenna can be further enhanced by using:

- An artificial metamaterial ground plane as a replacement to the truncated ground plane

- Replacing the single radiating element by a two or four element array of identical elements (i.e. array antenna)

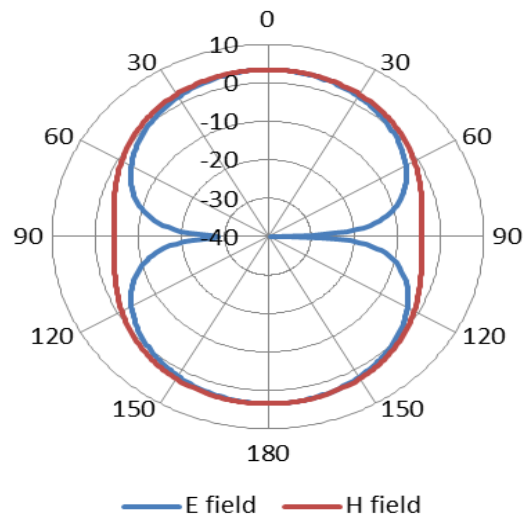

(a)

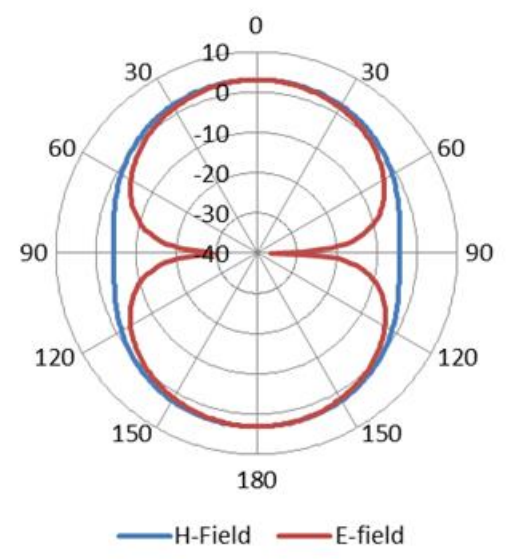

(b)

Fig.5. E and H-planes pattern of the proposed antenna at $2.45 \mathrm{GHz}$ (a) Directivity (b) Gain

The radiated electric $(E)$ and magnetic $(H)$ fields of the antenna at $2.45 \mathrm{GHz}$ are portrayed in Fig. $6 \mathrm{a}$ and b respectively. These plots clearly show the radiating length of the nominated antenna. The $E$ field is higher in the center of the lower (horizontal) arm, while minimum along the side (vertical) arms. The $H$ field is inversely related to the $E$ field therefore its intensity is higher along the vertical arms of the proposed antenna. 


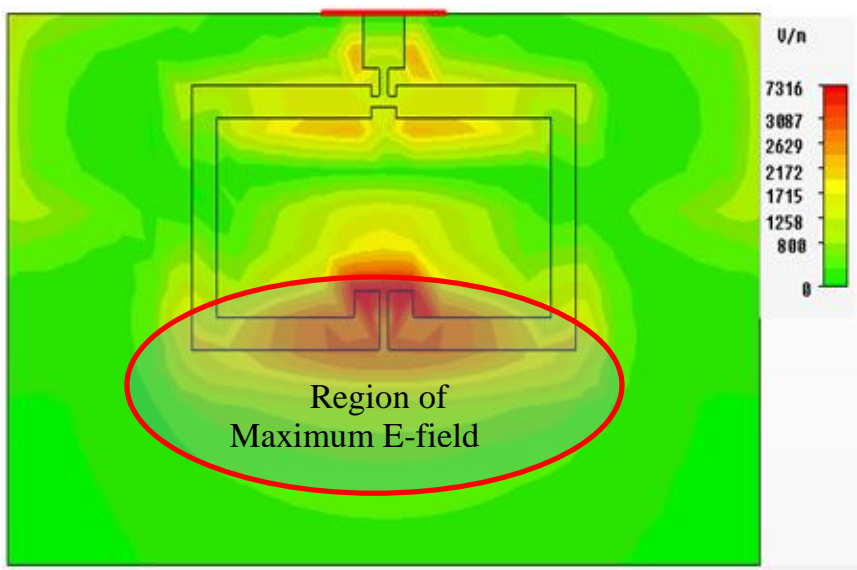

(a)

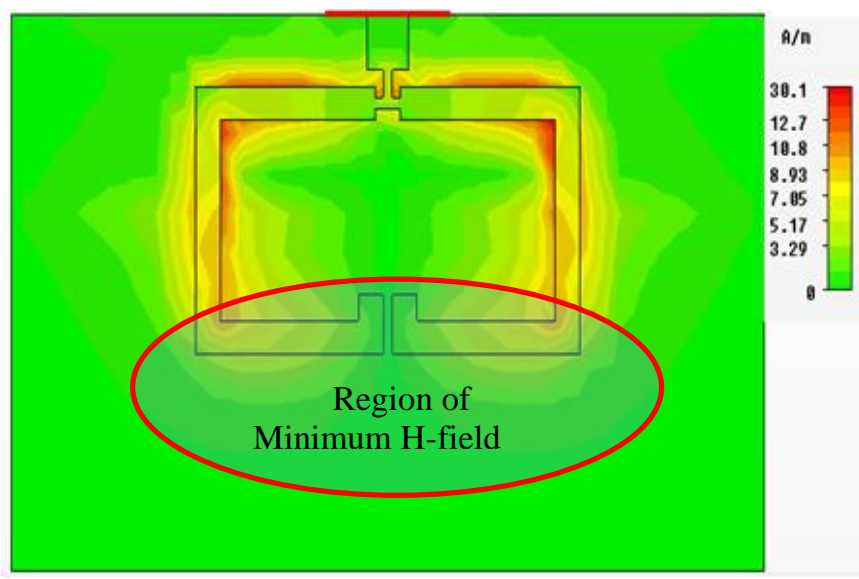

(b)

Fig.6. Radiated (a) E field and (b) $\mathrm{H}$ field, at $2.45 \mathrm{GHz}$

The three-dimensional plots of directivity and gain of the nominated antenna are portrayed in Fig. 7 and 8 respectively. A peak directivity and gain of the RFID antenna are $3.42 \mathrm{dBi}$ and $3.1 \mathrm{~dB}$ respectively at $2.45 \mathrm{GHz}$. The nominated antenna has an extremely good efficiency of $92.8 \%$ at $2.45 \mathrm{GHz}$ (Centered Frequency), due to the matched design procedure. The summary of the results is portrayed in Table 2 below:

Table 2. Summed up results

\begin{tabular}{ll}
\hline Parameters & Results \\
\hline Frequency (GHz) & 2.45 \\
Directivity (dBi) & 3.42 \\
Gain (dB) & 3.144 \\
Return Loss (dB) & -35.57 \\
Bandwidth (\%) & 12 \\
Efficiency (\%) & 92.8 \\
Impedance ( $\mathbf{\Omega})$ & 50.25 \\
VSWR (ratio) & 1.03 \\
\hline
\end{tabular}




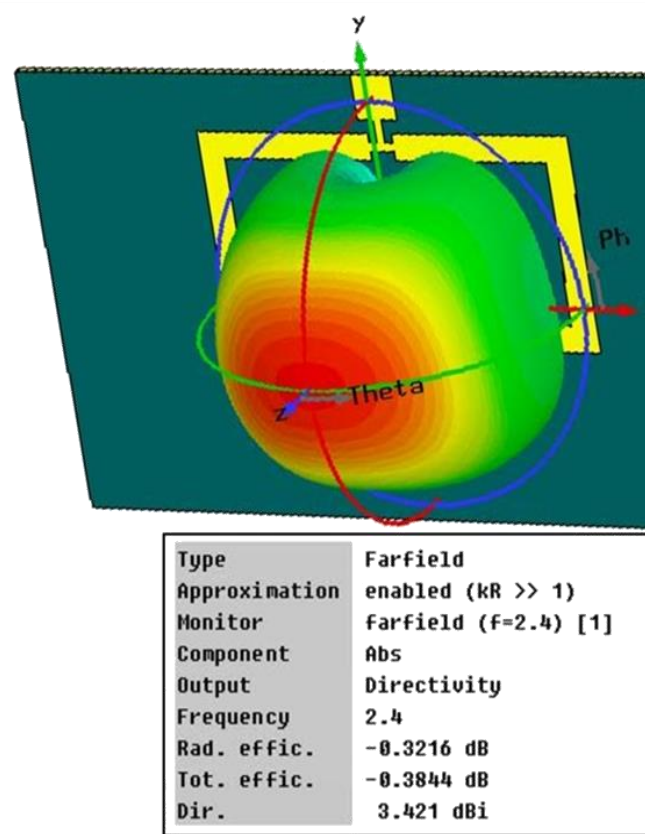

Fig.7. Far-field directivity pattern (3D) at $2.45 \mathrm{GHz}$

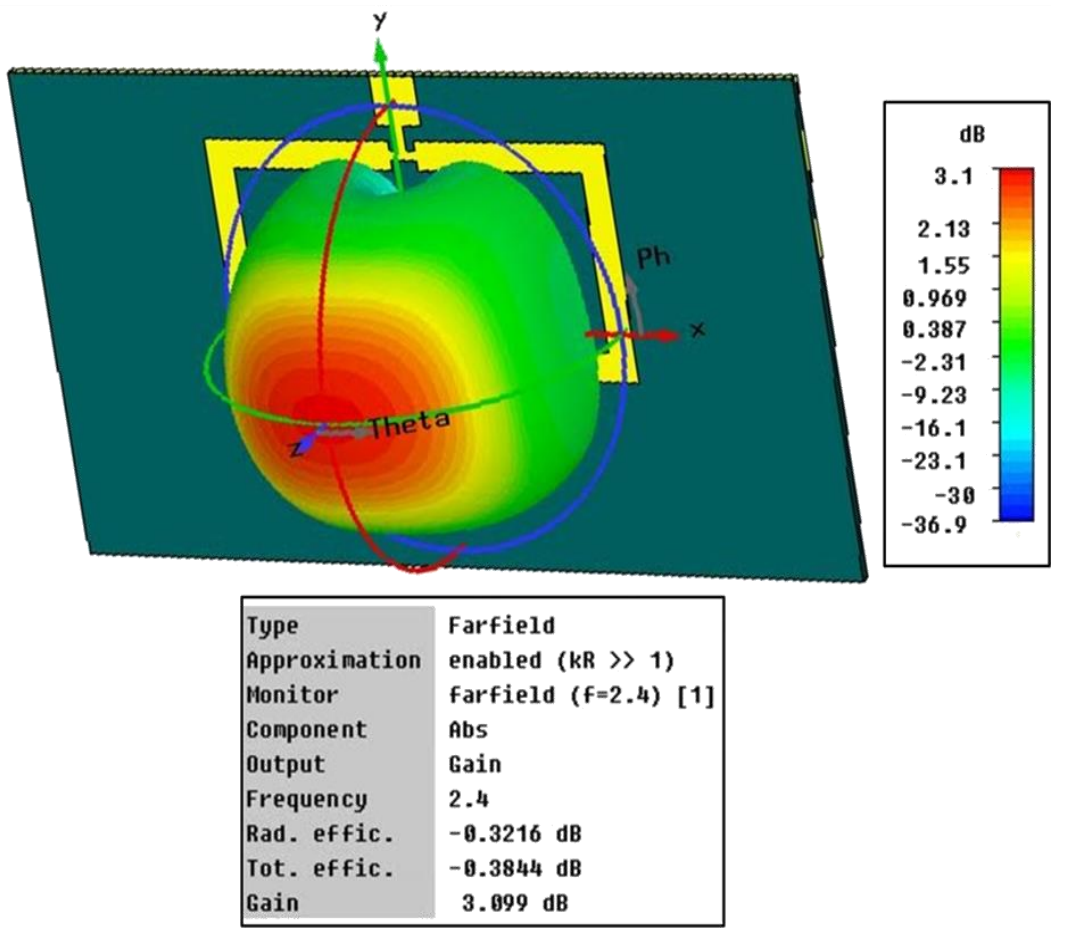

Fig.8. Far-field gain pattern (3D) at $2.45 \mathrm{GHz}$ 
The three dimensional far-field plots clearly show that the antenna radiates most of the power orthogonal to the plane of the antenna geometry. Negligible amount of power is radiated in the backward direction. Therefore the antenna can be safely used in wearable application s which demands for low level of backward radiations towards human body.

\section{Conclusions}

A single-band wearable and planar rectangular C-shaped monopole antenna for RFID (2.45 GHz) has been presented in this paper. The C-shaped planar monopole antenna work highly efficiently $(92.8 \%)$ at $2.45 \mathrm{GHz}$, due to a truncated coper ground plane and extremely matched feeding mechanism.

Bandwidth of $12 \%$ (294 MHz), relative to $-10 \mathrm{~dB}$ threshold of return loss, has been achieved at $2.45 \mathrm{GHz}$. The far-field pattern of the nominated antenna is acclaimed to be omni-directional, with a relatively good gain of $3.144 \mathrm{~dB}$ due to good impedance matching at $2.45 \mathrm{GHz}$. The nominated $\mathrm{C}$-shaped monopole antenna can be used in RFID applications such as medical implants, remote patient monitoring, rescue and military operations.

The truncated ground plane can be replaced by an electromagnetic bandgap structure for further better gain, directivity, efficiency and reduced level of Specific Absorption Rate (SAR) in wearable scenarios. The effects of bending and crumpling on antenna performance parameters can also be studied in body worn conditions Furthermore the antenna can be reconfigured in dual and triple band modes, using optical or PIN diode switches in order to add other dedicated RFID frequency bands. The prototype of the proposed antenna will be fabricated to validate the numerical results.

\section{Acknowledgements}

The authors of this manuscript thankfully acknowledge, CST MWS for the simulation tool for conducting the numerical analysis of the proposed antenna. We are also grateful to the Higher Education Commission of Pakistan for supporting this research.

\section{References}

[1] Bolic, Miodrag, David Simplot-Ryl, and Ivan Stojmenovic, eds. RFID systems: research trends and challenges. John Wiley \& Sons, 2010.

[2] Mobashsher, Ahmed Toaha, Mohammad Tariqul Islam, and Norbahiah Misran. "A novel high-gain dualband antenna for RFID reader applications." Antennas and Wireless Propagation Letters, pp. 653-656, 2010.

[3] Abu, Maisarah, and Mohamad Kamal Abd Rahim. "Triple-band printed dipole antenna for RFID." Progress in Electromagnetics Research, pp. 145-153, 2009.

[4] Grosinger, Jasmin, and Michael Fischer. "Evaluating on-body RFID systems at $900 \mathrm{MHz}$ and $2.45 \mathrm{GHz} . "$, IEEE international workshop on RFID Technology (EURASIP RFID), pp. 52-58, 2012.

[5] Osman, Mai AR, M. K. A. Rahim, N. A. Samsuri, and Mohammed E. Ali. "Compact and embroidered textile wearable antenna." IEEE International conference on RF and Microwave (RFM), pp. 311-314, 2011.

[6] Rais, N. H. M., Ping Jack Soh, F. Malek, S. Ahmad, N. B. M. Hashim, and P. S. Hall. "A review of wearable antenna." IEEE international conference on Antennas \& Propagation, pp. 225-228, Loughborough, 2009.

[7] Salonen, Pekka, Yahya Rahmat-Samii, and Markku Kivikoski. "Wearable antennas in the vicinity of human body."IEEE international symposium on In Antennas and Propagation,vol. 1, pp. 467-470, 2004.

[8] Panda, Jyoti Ranjan, Aditya Sri Ram Saladi, and Rakhesh Singh Kshetrimayum. "A compact printed 
monopole antenna for dual-band RFID and WLAN applications." Radio engineering, PP. 2011.

[9] Zhang, G-M., J-S. Hong, B-Z. Wang, Q-Y. Qin, B. He, and D-M. Wan. "A novel planar monopole antenna with an H-shaped ground plane for dual-band WLAN applications." Journal of Electromagnetic Waves and Application, pp.2229-2239, 2007.

[10] Shu, Panlin, and Quanyuan Feng. "Compact tri-band monopole antenna with a parasitic E-shaped strip for WLAN/WiMAX applications." Progress in Electromagnetics Research, pp.53-63, 2012.

[11] Iddi, H. U., M. R. Kamarudin, T. A. Rahman, and R. Dewan. "Design of dual-band B-shaped monopole antenna for MIMO application." IEEE international symposium on Antennas and Propagation (APSURSI), pp. 1-2, 2012.

[12] Wong, Shih-Huang Yehand Kin-Lu. "Dual-Band F-Shaped Monopole Antenna for 2.415. $2 \mathrm{GHz}$ WLAN Application." IEEE international symposium on Antennas and Propagation, vol. 4, pp. 72-75, 2002.

[13] Marzudi, W. N. W., and Z. Z. Abidin. "Dual-wideband G-shaped slotted printed monopole antenna for WLAN and WiMAX applications."IEEE international conference on RF and Microwave (RFM), pp. 225227 ,

[14] Li, Zengrui, Zhun Yang, Qingxin Guo, Junhong Wang, and Wenbo Jiang. "Printed triple-T monopole antenna for 2.4, 5.2, and 5.8 GHz WLAN operations." IET international conference on Microwave Technology and Computational Electromagnetics, ICMTCE,pp. 101-104, 2009.

[15] Hayat Errifi, Abdennaceur Baghdad, Abdelmajid Badri, Aicha Sahel. "Radiation Characteristics Enhancement of Microstrip Triangular Patch Antenna using Several Array Structures." International Journal of Wireless and Microwave Technologies(IJWMT), Vol. 5, No. 3, pp. 1-17, May 2015. DOI: 10.5815/ijwmt.2015.03.01.

[16] Omrane Necibi, Abdelhak Ferchichi, Tan-phu Vuong, Ali Gharsallah. "A Discussion of a $60 \mathrm{GHz}$ Meander Slot Antenna for an RFID TAG with Lumped Element." International Journal of Wireless and Microwave Technologies(IJWMT), Vol. 4, No. 2, pp. 1-11, March 2014. DOI: 10.5815/ijwmt.2014.02.01.

[17] Constantine A. Balanis, Antenna Theory Analysis and Design, 2nd Edition, New York: John Wiley \& Sons, pp.811-855, 1997.

[18] Hirtenfelder, Franz. "Effective antenna simulations using CST MICROWAVE STUDIO®." IEEE international conference on Antennas, ITG,pp. 239-239,2007.

\section{Authors' Profiles}

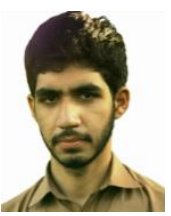

Hammad Khan is a research student in UET Peshawar, Pakistan in the Department of Telecommunication Engineering, UET Peshawar (Mardan Campus), Pakistan. Currently he is doing research on RFID antennas. His research interests include, planar antennas, millimeter wave antennas, Specific Absorption Rate analysis, Frequency Selective Surfaces and EBGs.

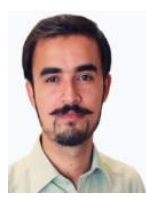

Ali Nasir is a research student in UET Peshawar, Pakistan in the Department of Telecommunication Engineering, UET Peshawar (Mardan Campus), Pakistan. Currently he is doing research on RFID antennas. His research interests include, planar antennas, Frequency Selective Surfaces and EBGs. 
Umar Bin Mumtaz is a research student in UET Peshawar, Pakistan in the Department of Telecommunication Engineering, UET Peshawar (Mardan Campus), Pakistan. Currently he is doing research on RFID antennas. His research interests include, planar antennas, Frequency Selective Surfaces and EBGs

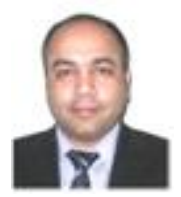

Sadiq Ullah is Assistant Professor at the Department of Telecommunication Engineering, University of Engineering \& Technology, Peshawar, Pakistan. Sadiq Ullah received B.Sc. Electrical Engineering from University of Engineering and Technology, Peshawar, Pakistan. He achieved his M.Sc. in Electrical Engineering from University of Engineering and Technology Taxila, Pakistan. In 2007, he joined the Department of Electronic and Electrical Engineering, at Loughborough University, U.K., and was awarded Ph.D. for his research in the field of design and measurement of metamaterial based antennas in 2010. He worked as an Assistant Manager (Electronics) in a public sector R and D organization in Islamabad, where his main responsibilities were hardware, software codesign, designing and testing of high precession electronics, test equipment. His research mainly focuses on design and measurement of low-profile antennas on electromagnetic Bandgap structures, RFID tag antennas and wearable antennas. He has been worked as a Research Associate at Loughborough University, where he researched on the propagation effects of rain, snow, ice, fog and forest in millimeter wave band. During his Ph.D., he published his research in international conferences and journals.

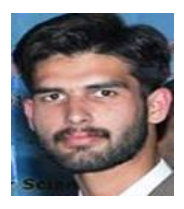

Syed Ahson Ali Shah is a research student in UET Peshawar, Pakistan in the Department of Telecommunication Engineering, UET Peshawar (Mardan Campus), Pakistan. Currently he is doing research on reconfigurable antennas. His research interests include planar antenna, millimeter wave antennas, multi band antennas, implanted antennas, Specific Absorption Rate analysis, Frequency Selective Surfaces and EBGs.

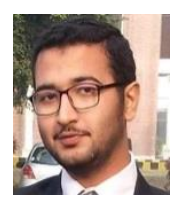

Muhammad Fawad Khan is a postgraduate research student in UET Peshawar, Pakistan in the Department of Telecommunication Engineering, UET Peshawar (Mardan Campus), Pakistan. Currently he is doing research on reconfigurable antennas. His research interests include, planar antennas, millimeter wave antennas, Specific Absorption Rate analysis, Frequency Selective Surfaces and EBGs.

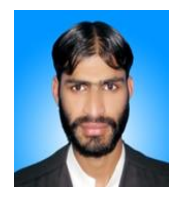

Usman Ali is a postgraduate research student in the Department of Telecommunication Engineering, University of Engineering and Technology (UET) Peshawar. He did his Bachelars from UET Peshawar in 2012. His research interests include metamaterials, signal processing, electromagnetic Bandgap structures and wearable antennas. Currently he is working as a Lab Engineer in the same Department.

How to cite this paper: Hammad Khan, Ali Nasir, Umar Bin Mumtaz, Sadiq Ullah, Syed Ahson Ali Shah, Muhammad Fawad Khan, Usman Ali,"Design and Analysis of a Wearable Monopole Antenna on Jeans Substrate for RFID Applications", International Journal of Wireless and Microwave Technologies(IJWMT), Vol.6, No.6, pp.24-35, 2016.DOI: 10.5815/ijwmt.2016.06.03 